\title{
A Coprodução dos Serviços Públicos: modelos e modos DE GESTÃO
}

\author{
The Coproduction of Public Services: models and management \\ methods
}

\section{Luís Moretto Neto}

Professor associado do programa de pós-graduação em administração da Universidade Federal de Santa Catarina. Instituição a qual está vinculado: Universidade Federal de Santa Catarina. Florianópolis, SC. Brasil.E-mail: luis.moretto.neto@ufsc.br

\section{Vanessa Marie Salm}

Gerente de Projetos. Instituto Stela; Vanessa Tobias Coaching; Doutoranda do programa de pós-graduação em Engenharia e Gestão do Conhecimento da Universidade Federal de Santa Catarina (UFSC). Florianópolis, SC. Brasil. E-mail: vmsalm@hotmail.com

\section{Victor Burigo}

Acadêmico do curso de Mestrado em Administração. Universidade Federal de Santa Catarina (UFSC). Lages,SC. Brasil.

E-mail: victorburigosouza@gmail.com

\section{Resumo}

Este trabalho tem o objetivo de identificar as principais características que integram o modo de gestão de cada um dos modelos de coprodução dos serviços públicos. Com esse foco são discutidas as características dos modelos da administração pública para definir as categorias de análise utilizadas ao longo do ensaio. A partir das categorias de análise, são levantadas e ordenadas as características dos modos de gestão das organizações públicas e da gestão social. Fundamentados nesses modos de gestão e no referencial teórico, que sustenta este artigo, são identificadas as características do modo de gestão de cada um dos modelos de coprodução de serviços públicos.

Palavras-chave: Coprodução. Modo de Gestão. Administração Pública. Gestão Social.

\section{Abstract}

The test aims to identify the main features that integrate the management mode of each of the models of coproduction of public services. With this focus we discuss the characteristics of the models of public administration to define the categories of analysis used throughout the test. From the categories of analysis are raised and ordered the characteristics of the modes of management of public organizations and social management. Based on these management modes and theoretical framework, which supports the testing are identified the characteristics of the administration of each of the models of coproduction of public services.

Keywords: Coproduction. Management Mode. Public Administration. Social Management. 


\section{INTRODUÇÃo}

A administração pública passa por um momento singular, pois ela também reflete, sob diversos ângulos, as transformações que vêm ocorrendo na sociedade. Nesse sentido, ela se caracteriza pela imanência, ora influenciando e ora sendo influenciada pelo processo histórico em construção. No passado a administração pública seguiu um viés apenas burocrático, na história recente ela assumiu os predicados do mercado e, nesse momento, está se adaptando à demanda da sociedade por mais democracia, transparência, responsividade, eficácia, eficiência, participação e, inclusive, pela coprodução dos serviços públicos.

Esse processo torna o trabalho do pesquisador mais instigante, já que não é mais possível morar, exclusivamente, no passado, e, tampouco por demais no presente. Se o trabalho de pesquisa pretende contribuir com a formulação de teorias, é preciso estar em processo de contínua transição para o futuro, amparado pela possibilidade objetiva a que se refere Ramos (2014), sem falir perante os ditames que a ciência impõe. Nesse limiar de uma realidade em permanente construção e reconstrução se encontra um processo denominado por Schon (1973) "conservadorismo dinâmico" e por Ramos (2014) "contextualismo dialético". É, pois, uma visita permanente ao quase futuro da história, sem perder de vista a realidade presente. O tema principal deste ensaio se insere nesse contexto, pois ele trata da estratégia da administração pública para a coprodução dos serviços públicos e de seus modelos. Dentro desse tema, o foco específico do ensaio são as características dos modos de gestão de cada um dos modelos de coprodução dos serviços públicos.

A coprodução dos serviços públicos é uma estratégia para a produção dos serviços públicos de que podem participar o aparato público do Estado, as organizações privadas e do terceiro setor, além de arranjos comunitários e do cidadão que, no conjunto, compartilham entre si responsabilidades e poder (SALM, 2014). O fenômeno da coprodução é identificável na realidade, uma vez que se pode constatar, mesmo de forma empírica, a presença de organizações do terceiro setor, empresas via área de responsabilidade social, comunidades e mesmo cidadãos que, junto com o aparato burocrático do Estado, produzem serviços públicos.
É importante ressaltar que a coprodução dos serviços públicos, nesse momento, tem o corolário de suas premissas ancorado nas demandas da sociedade por mais transparência, eficiência, participação e controle social sobre o aparato burocrático do Estado. Passa a ser imperativo, portanto, que a administração pública estude mais esse fenômeno, identificando as características dos modos de gestão que se aplicam aos modelos de coprodução dos serviços públicos, principalmente daqueles em que ocorre elevado grau de participação do cidadão. A relevância deste estudo está ancorada na ausência de elaboração teórica sobre os modos de gestão da rede de coprodução dos serviços públicos, principalmente das características do modo de gestão que se aplica a cada um dos modelos de coprodução.

Devido a essa lacuna, o ensaio tem como objetivo identificar as principais características que integram o modo de gestão de cada um dos modelos de coprodução dos serviços públicos.

Com foco nesse objetivo, o ensaio, após essa (1) introdução, apresenta o (2) referencial teórico, que dá suporte aos argumentos desenvolvidos ao longo do trabalho; e discute (3) os modelos de administração pública e as suas características. Na sequência, também serão discutidos a (4) coprodução dos serviços públicos, os modelos e suas características e os (5) modos de gestão das organizações públicas e da gestão social, ao mesmo tempo em que são identificadas as características do modo de gestão de cada um dos modelos de coprodução dos serviços públicos. O trabalho segue com a apresentação das (6) conclusões e das (7) referências utilizadas.

Presentes o objetivo e a organização deste ensaio, $e$, na ausência de maiores referenciais teóricos, que tratam dos modos de gestão da coprodução dos serviços públicos, torna-se necessária uma apropriação das principais características dos modelos da administração pública, e, a partir dessas características, a definição das categorias de análise que serão utilizadas ao longo deste ensaio. Com base nas categorias de análise são discutidas as características dos modos de gestão das organizações públicas e da gestão social. Com fundamento nessas características e no referencial teórico, que sustenta o ensaio, são identificadas as características do modo de gestão de cada um dos modelos de coprodução de serviços públicos. 


\section{Referencial Teórico}

Nos meios acadêmicos trava-se um longo debate sobre o conceito e o escopo da administração pública. Por outro lado, o questionamento dos alicerces científicos dessa área de ação na esfera pública também é motivo de frequentes disputas (Disputatio Sine Fine) em revistas e jornais acadêmicos. Sem entrar no mérito desses questionamentos, mesmo porque esse não é o objetivo que se persegue neste ensaio, é necessário ressaltar a importância da filosofia, da ciência política, da sociologia, da antropologia e, entre outros campos do conhecimento humano, da economia, para o entendimento da área de ação da administração pública. Assim, independentemente de ser ou não uma ciência e da sua abrangência (FADUL et al., 2012), a administração pública é influenciada por diversos campos de conhecimento, fato que lhe dá um caráter multidisciplinar e de complexidade.

A partir dessa assertiva é possível buscar nesses campos do conhecimento que interagem com a administração pública os referenciais básicos necessários ao alicerce que se necessita para o desenvolvimento deste trabalho. Assim, este ensaio toma por base a delimitação dos sistemas sociais, proposta por Ramos (1981), principalmente no que se refere ao ser humano e à esfera da ação pública. Os conceitos sobre esfera pública, ação humana e sobre a política seguem o pensamento de Arendt $(2009,2014)$, uma vez que as concepções teóricas e filosóficas da autora sobre esses temas são amplamente citadas e relevantes para o campo da administração pública. De acordo com esses autores, a ação humana na esfera pública é eminentemente política. Para Ramos (1981), o ser humano que realiza essa ação é multidimensional, ou seja, o ser humano é um ser político, comunitário e social, bem como integrante da natureza. Ainda, segundo esse autor, o ser humano é racional, capaz de exercer o cálculo de consequências - a racionalidade funcional - e capaz de avaliar a legitimidade das ações que decorrem desse cálculo - racionalidade substantiva. O autor acrescenta que o ser humano pode praticar ações dentro da ética da responsabilidade quando cumpre os ditames que a sociedade ou o grupo social lhes impõe; quando age lucidamente segundo as suas convicções, os seus atos se identificam como ética da convicção. A realidade que se afigura para a prática da vida em sociedade, em muitas ocasiões, pode levar ao conflito entre essas duas éticas. Passa a ser importante, também, que a comunidade seja o ser humano em escala ampliada (VOEGELIN, 1990). Perseguindo esse mesmo pensamento, para que a comunidade seja um habitat adequado à existência humana ela deve refletir a multidimensionalidade nos seus espaços que, de acordo com Arendt (2014), são denominados esfera pública e esfera privada. A existência desses espaços encontra a sua razão de ser, de acordo com Ramos (1981), pelo imperativo da autorrealização humana que, na sua essência, é uma exigência da vida humana, segundo a caracterização que, também, atribui Voegelin (1990) a esse índice linguístico.

A administração pública, quando se caracteriza como espaço no qual pode ocorrer o diálogo e a discussão, portanto, quando nela se pode exercer, também, a atividade da política, se identifica como esfera pública (STIEVERS, 2002). Nos demais casos, ela se ajusta aos ditames da esfera privada, com as suas formas de dominação e de alienação. Nesse caso, de acordo com Etzioni (1973), o poder se exerce de maneira coercitiva, remunerativa e normativa. O poder coercitivo é exercido mediante ameaças e penalização ou por ausência absoluta de participação e de consenso entre os membros da organização. O poder remunerativo se exerce pela distribuição de benefícios materiais aos membros da organização, a participação diz respeito às metas e à forma de realizar o trabalho; no que se refere às decisões estratégicas, há pouca participação e consenso. O poder normativo se exerce pelo uso de estímulos, manipulativos e simbólicos, para a obtenção do envolvimento das pessoas, há mais espaço para a participação e a realização do consenso, mesmo em assuntos de natureza estratégica. Ainda, de acordo com o mesmo autor, o envolvimento, nesse tipo de organização, pode ser alienativo, calculativo e moral. O envolvimento alienativo se realiza mediante condicionamento, em elevado grau, das pessoas que integram a organização. Nesse caso, os benefícios pessoais são quase nulos. O envolvimento calculativo ocorre por meio da concessão de benefícios materiais e simbólicos dirigidos à consecução dos objetivos organizacionais e, excepcionalmente, pessoais. O envolvimento moral resulta da busca dos objetivos organizacionais e de apelos associados ao significado e objetivo de vida dos membros da organização. Nesse caso, a participação 
dos membros da organização é elevada em todos os sentidos.

Quanto à concepção que se tem do ser humano, a multidimensionalidade humana perpassa a administração pública e os seus modos de gestão quando eles compõem a esfera pública, exigindo no seu escopo de ação, também, a presença da política para o pleno êxito de suas atividades. Essa linha de argumentação supera o debate sobre a dicotomia da técnica e da política em torno da administração pública. Também define a participação, por meio do exercício do diálogo e da discussão, como necessária ao exercício da administração pública e, principalmente, aos modos de gestão em uso no seu espaço. Essa asserção encontra na realidade de nossos dias o seu corolário, mesmo porque a sociedade, como ficou evidente em diversas demonstrações de rua, está exigindo daqueles que exercem a política mais responsabilidade e transparência; e do aparato público do Estado estão exigindo a produção de serviços públicos com mais eficiência, eficácia, transparência, responsividade e participação. A responsividade se refere ao atendimento, pelas organizações públicas, das demandas e das expectativas da população, inclusive com relação à participação nas decisões. Destaca-se, ainda, que as manifestações apontam para a necessidade de uma gestão mais eficiente e eficaz na administração pública, com mais participação, diálogo e discussão política. Seguindo essas demandas, as características que identificam os modos de gestão dos modelos de coprodução dos serviços públicos devem incluir os primados da multidimensionalidade humana. Essa também é a principal premissa que sustenta os argumentos deste ensaio.

A administração pública e a gestão podem ser estudadas, para a compreensão de suas características e de sua ação administrativa, por meio de modelos que são uma abstração e simplificação da realidade. Os modelos de administração pública e de gestão foram articulados ao longo do tempo, refletindo o formato politico da sociedade na qual eles se inserem. No que diz respeito, especificamente, aos modelos de administração pública, este ensaio se alinha pelo trabalho de Denhardt e Denhardt (2011), dele extraindo a descrição que se faz sobre esse tema. $\mathrm{O}$ trabalho desses autores permite que se insira em cada modelo, por eles proposto, a coprodução dos serviços públicos, atribuindo-lhe, dessa forma, características próprias.
Considerando que o objetivo deste ensaio é identificar as características do modo de gestão de cada um dos modelos de coprodução, torna-se importante incluir, também, estudos sobre a gestão social, especialmente sobre as suas principais categoria de análise. Essa inclusão dos estudos sobre a gestão social é necessária porque as organizações do terceiro setor que integram a coprodução se regem, muitas delas, por esse modo de gestão. Para os efeitos deste ensaio, esses estudos sobre gestão social seguem a orientação do trabalho de Pimentel e Pimentel (2010) e de Cançado, Tenório, e Pereira (2011).

As demais teorias que podem oferecer suporte aos argumentos deste ensaio serão apresentadas $e$ discutidas ao longo do texto e, na medida em que servirem de referencial à argumentação que deve levar à consecução do objetivo que se propõe atingir. Dentro desse escopo, no tópico que segue, serão descritas e discutidas as principais características dos modelos de administração pública, com o propósito primeiro de se obter as categorias de análise de que se fará uso para definir as características do modo de gestão de cada um dos modelos de coprodução dos serviços públicos.

\section{Os Modelos de Administração Pública e as suas Características}

Realizada essa breve discussão e a descrição da base teórica que dá suporte ao ensaio, parte-se agora para a apresentação e a discussão dos modelos de administração pública e suas características. A discussão desses modelos e, principalmente, de suas características é relevante para os propósitos deste ensaio, já que permite examinar, com mais acuidade, a relação entre os modelos de coprodução e os modos de gestão em uso nas organizações públicas. Também é relevante porque permite identificar, a partir das características de cada modelo de administração pública, as categorias de análise que nele se fazem presentes. Essas categorias de análise permitem identificar, como se demonstra ao término deste ensaio, as características do modo de gestão de cada um dos modelos de coprodução dos serviços públicos.

O primeiro modelo denominado de velha administração pública se caracteriza pela organização burocrática sob o domínio do Estado. Esse modelo, 
sob o manto da impessoalidade, por um longo período, serviu aos propósitos de produção dos serviços públicos para o cidadão. Apesar da crítica que se faz a esse modelo ou mais precisamente à organização burocrática, conforme pode ser constatado em muitos trabalhos que tratam desse tema, esse modelo ainda está em uso no aparato público. A racionalidade funcional orienta a velha administração pública, e a ética da responsabilidade norteia as suas ações. Sob essa ótica, o poder que se exerce no seu espaço, dependendo do estilo de gestão das pessoas é coercitivo, remunerativo ou normativo, com ênfase nas duas primeiras alternativas, e o envolvimento das pessoas pode ser alienativo, calculativo ou moral, também com ênfase nas duas primeiras alternativas face ao caráter formal que reveste as organizações públicas. O interesse público, para esse modelo, é definido na esfera do poder político, cabendo ao aparato público do Estado realizar os serviços públicos de acordo com o que estipulam a lei e as normas.

A transparência e a responsividade ocorrem de acordo com o que determinam as leis, principalmente naquilo que diz respeito às relações hierárquicas $e$ aos poderes constituídos no âmbito do Estado. Nesse modelo, o Estado é o protagonista da administração pública e do seu modo de gestão que se alinha segundo as características desse modelo.

A nova gestão pública é o segundo modelo de gestão pública e se caracteriza pela utilização da organização burocrática, pública e privada, que privilegia o mercado e as suas praticas para a prestação dos serviços públicos. Esse modelo foi amplamente utilizado na segunda metade do século passado e início deste. A exagerada importância dada ao mercado como alocador dos serviços públicos e a descaracterização da administração pública pelo emprego das tecnologias das organizações privadas levaram ao enfraquecimento desse modelo (TAO; McCABE, 2012). Tal modelo se orienta pela racionalidade funcional e pela prática da ética da responsabilidade. O poder é exercido no âmbito desse modelo de maneira coercitiva e, principalmente, remunerativa. O envolvimento das pessoas na organização pública é alienativo e calculativo. O interesse público é entendido como a somatória dos interesses individuais. Nesse modelo, cabe ao mercado a primazia da prestação dos serviços públicos, possibilitando a coprodução desses serviços públicos.
Mas sempre sob a ótica da eficiência dos meios e do interesse do consumidor ou do cliente. A transparência $e$ a responsividade se realizam de acordo com o que prescreve a lei e a partir das exigências da competição de interesses. O modelo serve aos propósitos de produção dos serviços públicos para o cidadão agora entendido como cliente ou consumidor, também sob o manto do trato da impessoalidade. O Estado via mercado é o protagonista desse modelo. O modo de gestão predominante nesse modelo se alinha de acordo com essas características.

O terceiro modelo de administração pública é o do novo serviço público. Ele é um modelo emergente $e$, assim como os demais, tem um caráter normativo, além de se configurar como modelo ideal. Weber (2004) ao tratar desse tipo de modelo, lhe deu uma conotação heurística. Ramos (2006), em seu trabalho sobre essa temática, afirma que modelos ideais são abstrações e simplificações da realidade, por isso, não se pode esperar que eles se realizem na íntegra. Os fundamentos desse modelo se estruturam na democracia e no interesse público, segundo Denhardt $e$ Denhardt (2011), autores dessa proposta e de suas premissas. Por se tratar de modelo emergente que ancora os seus princípios nos pensadores clássicos gregos, ele proporciona uma orientação normativa ampla. Portanto, ele se caracteriza mais como uma orientação para administração pública, mesmo porque advoga a premissa de que os serviços públicos são coproduzidos pelo aparato público do Estado, as organizações não governamentais que permeiam a sociedade, as comunidades e pelo cidadão. Desse modo, o novo serviço público se caracteriza pela rede que coproduz os serviços públicos, seguindo a normativa das premissas que o constituem. Entre essas premissas cabe citar: servir ao cidadão, não a consumidores ou clientes; buscar sempre o interesse público; valorizar sempre a cidadania sobre o empreendedorismo; pensar estrategicamente, mas agir democraticamente; servir, ao invés de dirigir a sociedade e valorizar as pessoas, não apenas a produtividade. Seguindo essas premissas, é possível perceber que o novo serviço público se orienta a partir da racionalidade funcional $e$ da racionalidade substantiva e pela ética da responsabilidade e da convicção.

A liberdade para agir, como Arendt (2014) concebeu o conceito de ação humana, é maior nesses 
modelos do que nos anteriores, pois a coprodução enseja uma inter-relação de organizações burocráticas e outras menos formais, algumas com configuração substantiva (RAMOS, 1981), que podem ser encontradas em arranjos comunitários que se articulam para prover serviços públicos e apoiar populações em risco, pessoas que precisam de algum serviço especial, preservação ambiental, projetos de educação, entre outros. O poder é visto nesse modelo como remunerativo e normativo, com foco principal neste último. O envolvimento das pessoas é calculativo e moral, com destaque para o envolvimento moral. A transparência e a responsividade são essenciais para o modelo, embora se reconheça que a sua realização não é simples. Conquanto o Estado seja o protagonista da administração pública, os serviços públicos são prestados pela rede de coprodução que serve ao cidadão. Nesse modelo, o modo de gestão diverge dos modelos anteriores, uma vez que a gestão não é de uma organização burocrática apenas, mas de uma rede de que participam organizações burocráticas, organizações não governamentais, algumas também burocráticas, grupos comunitários e cidadãos. Nesse caso, os modos de gestão das organizações burocráticas devem ser complementados ou reformulados a partir da concepção que Arendt (2009) empresta à liberdade; Ramos (1981), à racionalidade substantiva; e Denhardt e Denhardt (2011), ao interesse público. Como se observa, o modelo do novo serviço público requer a participação do cidadão, não apenas como produtor do serviço público, mas também como ente político que age na esfera pública.

As características expressas nessa breve discussão sobre cada um dos modelos de administração pública permitem que agora se possa identificar as categorias de análise contidas em cada um dos modelos. Essas categorias devem orientar o ordenamento das caraterísticas de gestão, uma vez que os modelos de administração pública guardam uma relação muito próxima com os seus modos de gestão, como se deduz da leitura de Ramos (1983).

As categorias de análise contidas nessas características são as seguintes: bases que sustentam o modelo; interesses preponderantes; objetivo da organização em cada modelo, tipo de racionalidade; ética privilegiada pelo modelo; protagonista na produção dos serviços públicos; liberdade de agir; tipo de participação; tipo de envolvimento dos membros da organização em cada modelo; tipo de poder; transparência; responsividade; prestação de contas e envolvimento externo.

Essa breve descrição e a discussão dos modelos de administração pública, de suas características e da identificação das categorias de análise devem ser complementadas, agora, com a discussão da coprodução de suas características e de seus modelos.

\section{A Coprodução dos Serviços Públicos: Modelos e características}

Neste tópico serão discutidos os principais conceitos, teorias e modelos de coprodução. Aqui, também, serão associadas as características e as categorias identificadas nos modelos de administração pública aos modelos de coprodução dos serviços públicos. Essas associações têm como objetivo identificar as características do modo de gestão de cada um dos modelos de coprodução dos serviços públicos.

As primeiras manifestações sobre coprodução na área acadêmica remontam à década de 1970. Com o advento da Proposição n. 13, do Estado da Califórnia, que impunha limites fiscais ao orçamento, houve necessidade de recorrer a outras estratégias de produção dos serviços públicos. Nessas circunstâncias, o Estado, Condados e Municípios passaram a envolver o cidadão, os grupos sociais e outros arranjos organizacionais na produção dos serviços públicos. Atualmente, de acordo com Cepiku e Giordano (2013), a coprodução dos serviços públicos se faz presente em trabalhos acadêmicos, os mais diversos, em países como Polônia, Portugal, Itália, Inglaterra, Holanda, Estados Unidos, Eslovênia, Canadá, Brasil, Austrália, bem como em países da África e da Ásia.

A coprodução dos serviços públicos se caracteriza pelo envolvimento de organizações formais, públicas e privadas, organizações não governamentais, grupos da comunidade e cidadãos que podem compartilhar entre si responsabilidades e poder na produção dos serviços públicos. A coprodução pode ocorrer pelo ajustamento entre essas organizações, assim como pela constituição de uma rede que coproduz serviços públicos.

No primeiro caso, o aparato do Estado repassa recursos ou contrata serviços. O Estado, nesse formato de coprodução, exerce o protagonismo e a hegemonia, que ocorre quando associações ou organizações não 
governamentais de natureza caritativa ou de voluntariado prestam serviços para a comunidade ou segmentos sociais que necessitam dos seus serviços. Também pode ocorrer quando o Estado contrata serviços com organizações de mercado ou do terceiro setor. Nesses casos, o protagonismo e a hegemonia também são do Estado. Esse formato de coprodução pode ocorrer por solicitação, assistência ou por simples ajuste mútuo entre participantes da coprodução. (WHITAKER, 1980)

A coprodução dos serviços públicos, quando realizada por meio de uma rede, associa organizações públicas, privadas, não governamentais, arranjos comunitários e cidadãos que interagem para a produção dos serviços. Nesses casos não ocorre um ajustamento com protagonismo absoluto do Estado, mas um compartilhamento de responsabilidades e de poder entre os participes da rede. Pela legislação em vigor no Brasil, a coordenação e controle da rede sempre cabem ao Estado.

Os serviços públicos prestados por meio de coprodução em que ocorre ajustamento entre organizações e cidadãos, solicitação de serviços ou simples assistência de serviços são próprios do modelo da velha administração pública. Usualmente, as características desse modelo também se fazem presentes na coprodução dos serviços. Além disso, a participação dos membros da sociedade e de suas organizações na coprodução se dá de forma passiva, seja por meio de trabalho voluntário, caritativo ou de simples ator coadjuvante na prestação dos serviços públicos, podendo variar esses formatos de comunidade para comunidade (SUNDEEN, 1985). Nesse caso, também, são importantes a tecnologia, a economia $e$ as instituições para a prestação dos serviços (KISSER; PERCY, 1980). O envolvimento das pessoas da sociedade pode ocorrer, em algumas circunstâncias, para demonstrar a presença do Estado ou uma pretensa participação dos cidadãos, constituindo uma estratégia manipulativa apenas.

O modelo da nova gestão pública utiliza estratégias de coprodução para tornar os serviços públicos mais eficientes, principalmente na relação entre custo e benefício. O consumidor, ou o cliente, participa da prestação dos serviços para torná-los mais efetivos e menos onerosos. As recompensas que são oferecidas ao cidadão para participar da prestação dos serviços, de acordo com Alford (2002), também são importantes indutores da coprodução. O princípio que rege a co- produção dos serviços públicos dentre esse modelo é o do menor custo e da produção de resultados. Nesse caso, além de organizações públicas, podem participar as organizações do mercado na produção dos serviços, tornando a sua prestação mais competitiva. As características da nova gestão pública se incorporam à coprodução dos serviços públicos realizados sob o foco desse modelo.

A prestação dos serviços públicos que seguem o modelo do novo serviço público, sob a forma de coprodução, se fundamenta nas premissas que orientam esse modelo, principalmente nos predicados da democracia, no interesse público e no ato de servir ao cidadão. Para Jakobsen (2013) e Osborne, Radnor e Nasi (2012), a oportunidade que o aparato público do Estado cria para as pessoas participarem da coprodução é fundamental, pois promove a democracia, a transparência e a responsividade. Essa participação e o envolvimento das pessoas se caracterizam como ação política dirigida à produção dos serviços públicos e ao fomento da democracia. A prestação dos serviços se caracteriza, ainda, pela transparência, responsividade e pelo protagonismo do Estado diante da rede de coprodução que serve ao cidadão. Esse protagonismo passa a ser exercido pela liderança do aparato público do Estado, nos moldes em que a descrevem De Mattia e Zappellini (2013). A participação do cidadão, nesse caso, é essencial e se constitui no principal parâmetro para a definição dos modelos de coprodução. (KLEIN JR et al., 2012)

As tipologias de participação propostas por Arnstein (1969), Pretty (1995) e White (1996) serviram de referência para Salm e Mengasso (2010) proporem modelos de coprodução dos serviços públicos. Os modelos são: coprodução nominal; coprodução simbólica; coprodução funcional; coprodução representativa com sustentabilidade e coprodução por meio da automobilização. A coprodução nominal é o compartilhamento de responsabilidades entre pessoas da sociedade, voluntários que realizam trabalho caritativo, para a prestação de serviços públicos. A coprodução simbólica é a prestação de serviços que envolve as pessoas da sociedade para demonstrar a presença do Estado, constituindo-se em uma forma de manipulação do cidadão pelo Estado. A coprodução funcional envolve o indivíduo, o grupo ou a coletividade na prestação dos serviços públicos com base em resultados e no 
menor custo, em outros termos, com base na eficiência. A coprodução representativa com sustentabilidade é o resultado da interação entre os cidadãos e as organizações da comunidade, que, no seu conjunto, produzem os serviços públicos. A coprodução por meio da automobilização comunitária ocorre quando a comunidade está permanentemente mobilizada e envolvida na realização dos serviços públicos, guiada por princípios éticos e de democracia participativa.

Esses modelos de coprodução podem ser associados aos modelos de administração pública e as suas categorias e características com base na discussão que se promoveu ao longo deste ensaio. Essa associação é particularmente importante para a definição das características do modo de gestão de cada um dos modelos de coprodução dos serviços públicos.

O modelo de coprodução nominal se coaduna com a velha administração pública cujas características, ordenadas de acordo com as categorias de análise, são as seguintes: bases do modelo são os valores organizacionais; interesse preponderante é a sociedade e a organização; objetivo da organização é produzir serviços públicos; racionalidade é funcional; ética é a da responsabilidade; protagonismo é do Estado; liberdade de agir é restrita; participação é restrita; envolvimento é alienativo/calculativo; poder é coercitivo/remunerativo; transparência se dá segundo a lei; prestação de contas é aos órgãos: legislativo e de contas; responsividade é à organização; envolvimento externo é esporádico.

O modelo simbólico pode ser incluído, com muitas ressalvas, na velha e na nova gestão pública. Por ser muito particular e exigir práticas manipulativas de massa na sociedade, não é possível definir exatamente qual é o modelo de administração pública a que ele pode ser associado. Por esse motivo não se associam ao modelo de coprodução simbólica um modelo de administração pública e as suas características.

O modelo de coprodução funcional é associado à nova gestão pública. Nesse caso, as características, ordenadas de acordo com as categorias de análise, são as seguintes: bases do modelo são os valores do mercado; interesse preponderante é o interesse individual; objetivo da organização é produzir serviços públicos para clientes; racionalidade é a funcional; ética é a da responsabilidade; protagonismo é do Estado e do mercado; liberdade de agir é restrita; participação é restrita; envolvimento é calculativo; poder é remunerativo; transparência se dá segundo a lei e a demando dos clientes; prestação de contas é aos órgãos legislativo e de contas e à clientela; responsividade é às demandas da clientela e à organização; envolvimento externo é com o mercado e a sociedade.

O modelo de coprodução representativa com sustentabilidade se alinha com o modelo de administração pública do novo serviço público. As características desse modelo, ordenadas de acordo com as categorias de análise, são as seguintes: bases do modelo são a democracia e interesse público; interesse preponderante é o público e servir ao cidadão; objetivo da organização é produzir serviços públicos para a comunidade e para o cidadão; racionalidade é a funcional e a substantiva; ética é a da responsabilidade e a da convicção; protagonismo é do Estado e da comunidade; liberdade de agir é ampla, com foco no interesse público; participação é necessária e ampla; envolvimento é calculativo/moral; poder é remunerativo/normativo; transparência se dá segundo a lei e o direito da comunidade; prestação de contas é aos órgãos legislativos e de contas e à comunidade; responsividade é à comunidade e ao cidadão; envolvimento externo é contínuo e permanente.

O modelo de coprodução por meio da automobilização é um constructo teórico do tipo ideal em que a articulação permanente da comunidade orienta a coprodução dos serviços públicos. Nesse caso, o protagonismo na coprodução dos serviços é o resultado da articulação permanente da comunidade, não do aparato público do Estado. As demais características são semelhantes as do modelo de coprodução representativa com sustentabilidade.

Essa associação dos modelos de coprodução dos serviços públicos com os modelos de administração pública, por meio das categorias de análise, também identifica as características que eles têm em comum. Essa relação deve servir, também, como orientação para definir as características dos modos de gestão de cada modelo de coprodução dos serviços públicos. É necessário, no entanto, identificar as características dos modos de gestão das organizações burocráticas e da gestão social, para compor um quadro final com as características do modo de gestão de cada um dos modelos de coprodução dos serviços públicos. É necessário relembrar que a gestão social é um importante componente da coprodução dos serviços públicos, em face da composição da rede em que participam 
organizações não governamentais, além de outros arranjos da comunidade.

O próximo tópico trata da gestão das organizações burocráticas, da gestão social e da definição das características do modo de gestão de cada um dos modelos de coprodução dos serviços públicos.

\section{Os Modos de Gestão das Organizações Públicas e da Gestão Social e a Definição do Modo de Gestão de Cada um dos Modelos de Coprodução dos Serviços Públicos}

Esse tópico trata dos modos de gestão que podem ocorrer nas organizações públicas, também da gestão social e das características de cada um dos modelos de coprodução dos serviços públicos. Em primeiro lugar se discute os modos de gestão das organizações públicas.

As organizações públicas adotam modos de gestão segundo o que determina a legislação $e$, a partir dela, estabelecem diversos formatos que abrangem um largo escopo cobrindo desde a maneira pessoal de exercer a gestão até aquela em que há o restrito cumprimento da forma da lei. Para cobrir esse largo espectro em que podem ocorrer os modos de gestão nas organizações públicas, faz-se uso da proposta de Chanlat (2000) sobre esse tema. Dá-se preferência a esse autor, porque a sua proposta continua atual e se coaduna com o largo espectro em que podem ocorrer os modos de gestão nas organizações públicas. O autor define modo de gestão como as práticas administrativas e de pessoal que a direção de uma organização utiliza para a consecução de objetivos. Os modos propostos pelo autor são: o modo tayloriano e neotayloriano; o modo de gestão tecnoburocrático; o modo de gestão baseado na excelência ou por resultados e o modo de gestão participativo.

O modo de gestão tayloriano e neotayloriano se caracteriza pela divisão muito fragmentada do trabalho; controles de tempo; tarefas repetitivas; divisão entre o planejamento e a execução; sistemas de controle rígido; o objetivo da organização e do indivíduo são diversos; o tipo de racionalidade é o funcional; a ética é a da responsabilidade; o protagonismo é da organização; a liberdade de agir é restrita; o tipo de participação é ape- nas na execução da tarefa; o tipo de envolvimento das pessoas é alienativo; o tipo de poder é, quase sempre, coercitivo; não há transparência e responsividade; a prestação de contas é formal e o envolvimento externo só existe quando a legislação assim o determina. Esse modo de gestão encontra reduzida possibilidade de aplicação nos modelos de administração pública, uma vez que as praticas administrativas nele utilizadas são próprias de algumas organizações privadas apenas. Por essa razão, esse modo de gestão será desconsiderado para a definição do modo de gestão de cada um dos modelos de coprodução dos serviços públicos.

O modo de gestão tecnoburocrático se caracteriza por valores eminentemente organizacionais; o interesse preponderante é o da organização; o objetivo da organização é social e organizacional; o tipo de racionalidade é o funcional; a ética é a da responsabilidade; o protagonismo é do Estado; a liberdade de agir é restrita ao desempenho da função; o tipo de participação é no desenvolvimento da tarefa; o tipo de envolvimento é alienativo e calculataivo, com preponderância do último; o tipo de poder é coercitivo e remunerativo, com preponderância deste último; a transparência é de acordo com a lei; a responsividade é restrita a definida na legislação; a prestação de contas segue a definição da legislação e o envolvimento externo é muito pequeno. Esse modo de gestão se identifica, principalmente, com as características da velha administração pública.

O modo de gestão da excelência se caracteriza por valores eminentemente organizacionais e de mercado; o interesse preponderante é o do cliente e o da organização; o objetivo da organização é prestar serviços ao cliente; o tipo de racionalidade é a funcional; a ética é a da responsabilidade; o protagonismo é do Estado e do mercado; a liberdade de agir é restrita ao desempenho da função e alcance dos objetivos; o tipo de participação se restringe ao desenvolvimento da tarefa e para definir o modo mais racional de produzir resultados; o tipo de envolvimento é o calculativo; o tipo de poder é o remunerativo; a transparência se dá de acordo com a lei e as exigências do cliente; a responsividade é à clientela; a prestação de contas segue a definição da legislação e com foco na clientela; já o envolvimento externo ocorre na medida da necessidade de satisfazer o cliente. Esse modo de gestão se identifica, principalmente, com as características da nova gestão pública. 
$\mathrm{O}$ modo de gestão participativo se caracteriza por valores organizacionais e de reconhecimento da responsabilidade humana no trato com os objetivos da organização; Prepondera o interesse público e da organização; o objetivo é prestar serviços ao cidadão dentro do interesse público; o tipo de racionalidade é o funcional com possiblidade de espaços para a prática da substantiva; a ética é a da responsabilidade e a da convicção; o protagonismo é do Estado e da comunidade; a liberdade de agir é ampla nos espaços de participação, mas restrita aos objetivos; o tipo de participação é amplo com foco no objetivo organizacional; o tipo de envolvimento é calculativo/moral; o tipo de poder é o remunerativo/normativo; a transparência segue a legislação e as demandas da comunidade; a responsividade se dirige para as demandas da sociedade; a prestação de contas segue a definição da legislação, com foco na comunidade; já o envolvimento externo é contínuo. Esse modo de gestão se identifica, principalmente, com as características do novo serviço público $e$, muito pouco, com as da nova gestão pública. Dada essa condição, esse modo de gestão será associado, apenas, ao modelo do novo serviço público.

Essa breve descrição dos modos de gestão e de suas características será complementada com a discussão da gestão social e de suas características, tomando-se por parâmetro as categorias de análise que têm orientado as discussões levadas a efeito neste ensaio. Essa tarefa visa agregar aos modos de gestão das organizações públicas conceitos e características da gestão social, permitindo que se definam, então, as características do modo de gestão de cada um dos modelos de coprodução.

A gestão social é um conjunto de práticas em que o diálogo e a discussão direcionam os esforços em prol do alcance dos objetivos que se dirigem ao bem comum da comunidade e do exercício da cidadania (CANÇADO; TENÓRIO; PEREIRA, 2011). A gestão social, de acordo com Boullosa e Schommer (2008), requer a prática de valores inerentes à democracia, participação, justiça, equidade e bem-estar social.
Para essas autoras, o conceito de gestão social está permanentemente em construção, mesmo porque a esfera pública em que ele se realiza, também, está em permanente articulação. A realização da gestão social, como se depreende do trabalho dessas autoras, se dá por meio de métodos de permanente interação com a comunidade e de liderança social. Nesse sentido, há uma perfeita integração entre a gestão social e os modelos de coprodução que privilegiam a participação ativa da comunidade e de suas organizações. Ainda dentro dessa perspectiva, a gestão ao incorporar princípios democráticos, de participação e de deliberação, se constitui em elemento essencial para o pleno êxito da coprodução dos serviços públicos.

Os princípios democráticos, de participação e de deliberação definem o alcance da gestão social na comunidade, assim como, as categorias que a caracterizam orienta as suas ações (CANÇADO; SAUSEN; VILLELA, 2013). Para os efeitos deste trabalho se faz uso das categorias e características da gestão social propostas por Pimentel e Pimentel (2010), já que esses autores repetidas vezes são citados, quando se trata desse tema. Também se optou por esses autores porque eles definiram, no seu estudo, um conjunto de categorias de análise semelhantes aquelas em uso nesse ensaio, permitindo-se uma confluência entre os modos de gestão adotados nas organizações públicas e na gestão social.

Na gestão social, o objetivo é o interesse coletivo de caráter público; o valor é a cooperação intraorganizacional e interorganizacional; racionalidade substantiva/ comunicativa; os protagonistas são os membros da sociedade civil organizada; a comunicação se faz mediante diálogo e discussão; o processo decisório se dá de forma descentralizada como construção coletiva; a operacionalização é social; a esfera da gestão social é a pública/social; no exercício do poder não há coerção; todos têm iguais condições de participação. O Quadro 1 apresenta as categorias de análise e as características dos modos de gestão pública e da gestão social. 
Quadro 1: Características dos modos de gestão pública e da gestão social

\begin{tabular}{|c|c|c|c|c|}
\hline \multirow{2}{*}{$\begin{array}{l}\text { Categorias de } \\
\text { Análise }\end{array}$} & \multicolumn{4}{|c|}{ Características do modo de Gestão } \\
\hline & TECNOBUROCRÁTICO & EXCELÊNCIA & Participativo & Social \\
\hline $\begin{array}{l}\text { Base do modo } \\
\text { de gestão }\end{array}$ & Organizacional & $\begin{array}{l}\text { Organizacional e } \\
\text { de mercado }\end{array}$ & $\begin{array}{l}\text { Organizacional e de } \\
\text { valorização humana }\end{array}$ & $\begin{array}{l}\text { Cooperação } \\
\text { intraorganizacional e } \\
\text { interorganizacional }\end{array}$ \\
\hline $\begin{array}{l}\text { Interesse } \\
\text { preponderante }\end{array}$ & Social e organização & Cliente e organização & Público e da organização & Público \\
\hline $\begin{array}{l}\text { Objetivo da } \\
\text { organização }\end{array}$ & Social e organizacional & Prestar serviços ao cliente & $\begin{array}{l}\text { Prestar serviços ao cidadão } \\
\text { dentro do interesse público }\end{array}$ & $\begin{array}{l}\text { Interesse coletivo de } \\
\text { caráter público }\end{array}$ \\
\hline Racionalidade & Funcional & Funcional & Funcional/Substantiva & $\begin{array}{l}\text { Substantiva/ } \\
\text { comunicativa }\end{array}$ \\
\hline Ética & Responsabilidade & Responsabilidade & $\begin{array}{l}\text { Responsabilidade/ } \\
\text { Convicção }\end{array}$ & $\begin{array}{l}\text { Não faz referência, } \\
\text { mas se deduz ser de } \\
\text { Responsabilidade } \\
\text { e Convicção }\end{array}$ \\
\hline Protagonismo & Estado & Estado e mercado & Estado e da comunidade & $\begin{array}{l}\text { Membros da sociedade } \\
\text { civil organizada }\end{array}$ \\
\hline Liberdade de agir & $\begin{array}{l}\text { Restrita ao desempenho } \\
\text { da função }\end{array}$ & $\begin{array}{l}\text { Restrita ao desempenho } \\
\text { da função e alcance } \\
\text { dos resultados }\end{array}$ & $\begin{array}{l}\text { Ampla nos espaços } \\
\text { de participação, mas } \\
\text { restrita aos objetivos }\end{array}$ & $\begin{array}{l}\text { Todos têm iguais } \\
\text { condições de agir }\end{array}$ \\
\hline $\begin{array}{l}\text { Participação dos } \\
\text { membros da } \\
\text { organização }\end{array}$ & $\begin{array}{l}\text { No desenvolvimento } \\
\text { da tarefa }\end{array}$ & $\begin{array}{l}\text { Restringe ao } \\
\text { desenvolvimento da } \\
\text { tarefa e ao modo } \\
\text { mais racional de } \\
\text { produzir resultados }\end{array}$ & $\begin{array}{l}\text { Amplo com foco no } \\
\text { objetivo organizacional }\end{array}$ & $\begin{array}{l}\text { Todos têm iguais } \\
\text { condições de } \\
\text { participação }\end{array}$ \\
\hline Envolvimento & Alienativo/ Calculativo & Calculativo & Calculativo/Moral & Coletivo \\
\hline Esfera & Pública/Privada & Pública/ Privada & Pública & Pública/social \\
\hline Poder & $\begin{array}{l}\text { Coercitivo/ } \\
\text { Remunerativo }\end{array}$ & Remunerativo & Remunerativo/ Normativo & Não há coerção \\
\hline Transparência & De acordo com a lei & $\begin{array}{l}\text { De acordo com a lei e } \\
\text { as exigências do cliente }\end{array}$ & $\begin{array}{l}\text { Segue a legislação e } \\
\text { demandas da comunidade }\end{array}$ & Ocorre sem restrições \\
\hline Prestação de contas & $\begin{array}{l}\text { Segue a definição } \\
\text { da legislação }\end{array}$ & $\begin{array}{l}\text { Definido pela legislação, } \\
\text { com foco na clientela }\end{array}$ & $\begin{array}{l}\text { Definição da legislação, } \\
\text { com foco na comunidade }\end{array}$ & À coletividade \\
\hline Processo Decisório & $\begin{array}{l}\text { Centralizado com } \\
\text { possibilidade de } \\
\text { participação segundo as } \\
\text { regras da organização } \\
\text { burocrática }\end{array}$ & $\begin{array}{l}\text { Centralizado em } \\
\text { questões estratégicas/ } \\
\text { descentralizado em } \\
\text { relação às metas } \\
\text { e à eficiência }\end{array}$ & $\begin{array}{l}\text { Descentralizado em cada } \\
\text { nível da organização }\end{array}$ & $\begin{array}{l}\text { Descentralizada, como } \\
\text { construção coletiva }\end{array}$ \\
\hline Responsividade & $\begin{array}{l}\text { Restrita a definida } \\
\text { na legislação }\end{array}$ & A clientela & $\begin{array}{l}\text { Dirigida para as demandas } \\
\text { da sociedade }\end{array}$ & $\begin{array}{l}\text { Aos membros da } \\
\text { sociedade }\end{array}$ \\
\hline $\begin{array}{l}\text { Envolvimento } \\
\text { externo }\end{array}$ & Muito reduzido & $\begin{array}{l}\text { Na medida da } \\
\text { necessidade de } \\
\text { satisfazer o cliente }\end{array}$ & Contínuo/Permanente & Permanente por definição \\
\hline
\end{tabular}

Fonte: Elaborado pelos autores a partir de Chanlat (2000) e de Pimentel e Pimentel (2010) 
Quadro 2: Síntese das características dos modos de gestão de cada um dos modelos de coprodução

\begin{tabular}{|c|c|c|}
\hline $\begin{array}{l}\text { Modelos de } \\
\text { Coprodução dos } \\
\text { SERviços PúBlicos }\end{array}$ & Conceitos & $\begin{array}{c}\text { Características do Modo de Gestão - Categorias que Orientam } \\
\text { o Modo de Gestão }\end{array}$ \\
\hline Nominal & $\begin{array}{l}\text { A coprodução nominal é uma estratégia } \\
\text { para a produção dos serviços públicos, } \\
\text { por meio de compartilhamento de } \\
\text { responsabilidades entre pessoas } \\
\text { da comunidade, preferencialmente } \\
\text { voluntários, e o aparato administrativo } \\
\text { público de Estado, com o propósito } \\
\text { apenas de tornar eficientes esses } \\
\text { serviços. }\end{array}$ & $\begin{array}{l}\text { Os valores são organizacionais; o interesse preponderante é o da } \\
\text { sociedade e da organização; objetivo é a produção dos serviços } \\
\text { públicos; a racionalidade é a funcional; a ética é a da responsabilidade; } \\
\text { o protagonismo é do Estado; a liberdade de agir é restrita; a participação } \\
\text { é restrita; o envolvimento é alienativo/calculativo; o poder é coercitivo/ } \\
\text { remunerativo; a transparência se dá segundo a lei; a prestação de contas } \\
\text { é aos órgãos legislativo e de contas; a responsividade é à organização; o } \\
\text { envolvimento externo é esporádico. }\end{array}$ \\
\hline Simbólica & $\begin{array}{l}\text { A coprodução simbólica é uma estratégia } \\
\text { para envolver os cidadãos na produção } \\
\text { dos serviços públicos para demonstrar a } \\
\text { presença do Estado. }\end{array}$ & $\begin{array}{l}\text { O modelo simbólico pode ser incluído, com muitas ressalvas, na velha e na } \\
\text { nova gestão pública. Por ser muito particular e exigir práticas manipulativas } \\
\text { de massa na sociedade, não é possível definir exatamente as características } \\
\text { que são próprias para o seu modo de gestão. }\end{array}$ \\
\hline Funcional & $\begin{array}{l}\text { A coprodução funcional é uma estratégia } \\
\text { utilizada pelo aparato público do Estado } \\
\text { para produzir os serviços públicos de } \\
\text { maneira mais eficiente e eficaz, com a } \\
\text { participação do indivíduo, do grupo ou } \\
\text { da coletividade. }\end{array}$ & $\begin{array}{l}\text { Os valores predominantes são os da burocracia; o interesse é o } \\
\text { interesse individual/privado; o objetivo é produzir serviços públicos para } \\
\text { clientes; a racionalidade é a funcional; a ética é a da responsabilidade; } \\
\text { o protagonismo é do Estado e do mercado; a liberdade de agir é } \\
\text { restrita; a participação é restrita; o envolvimento é calculativo; o poder } \\
\text { é remunerativo; a transparência segue a lei e a demando dos clientes; } \\
\text { a prestação contas é aos órgãos legislativos e de contas e à clientela; a } \\
\text { responsividade é à clientela e à organização; o envolvimento externo é } \\
\text { com a sociedade e a clientela. }\end{array}$ \\
\hline $\begin{array}{l}\text { Representativa com } \\
\text { Sustentabilidade }\end{array}$ & $\begin{array}{l}\text { A coprodução representativa com } \\
\text { sustentabilidade é o resultado da sinergia } \\
\text { que se estabelece na realização dos } \\
\text { serviços públicos de que participam } \\
\text { os cidadãos, as organizações da } \\
\text { comunidade e o aparato administrativo } \\
\text { do Estado que, no seu conjunto, } \\
\text { interagem em prol do bem comum. }\end{array}$ & $\begin{array}{l}\text { Os valores predominantes são os da democracia e os do interesse } \\
\text { público; o interesse preponderante é o público e servir ao cidadão; } \\
\text { o objetivo é produzir serviços públicos para a comunidade e para o } \\
\text { cidadão; a racionalidade é a funcional e a substantiva; a ética é a da } \\
\text { responsabilidade e a da convicção; o protagonismo é do Estado e da } \\
\text { comunidade; a liberdade de agir é ampla, com foco no interesse público; } \\
\text { a participação é necessária e ampla; o envolvimento é calculativo/moral; } \\
\text { o poder é remunerativo/normativo; a transparência segue a lei e o direito } \\
\text { da comunidade; a prestação de contas é aos órgãos legislativos e de } \\
\text { contas e à comunidade; a responsividade é à comunidade e ao cidadão; } \\
\text { o envolvimento externo é contínuo e permanente. }\end{array}$ \\
\hline $\begin{array}{l}\text { Para a } \\
\text { Automobilização } \\
\text { Comunitária }\end{array}$ & $\begin{array}{l}\text { A coprodução para a mobilização } \\
\text { comunitária é uma estratégia para a } \\
\text { realização dos serviços públicos de que } \\
\text { participa toda a comunidade, orientada } \\
\text { por princípios éticos e pela democracia } \\
\text { normativa, com o propósito de } \\
\text { manter a sociedade permanentemente } \\
\text { mobilizada. }\end{array}$ & $\begin{array}{l}\text { O modelo de coprodução por meio da automobilização é um constructo } \\
\text { teórico do tipo ideal em que a articulação permanente da comunidade } \\
\text { orienta a coprodução dos serviços públicos. Nesse caso, o protagonismo } \\
\text { na coprodução dos serviços é o resultado da articulação permanente da } \\
\text { comunidade, não do aparato público do Estado. As demais características } \\
\text { se assemelham as do modelo de coprodução representativa com } \\
\text { sustentabilidade. }\end{array}$ \\
\hline
\end{tabular}

Fonte: Elaborado pelos autores a partir da proposta de modelos de coprodução de Salm e Menegasso (2010) 
Como se constata por essa síntese e pela discussão levada a efeito ao longo deste ensaio, as caraterísticas do modo de gestão pública tecnoburocrática são inerentes ao modelo de coprodução nominal. As características do modo de gestão por excelência são próprias do modelo de coprodução funcional. Aquelas do modo de gestão participativa podem ser aplicadas ao modelo de coprodução representativa com sustentabilidade e ao modelo para a automobilização comunitária. As características do modo de gestão participativa, quando aplicadas ao modelo do novo serviço público, guardam muita semelhança com as características da gestão social. Tanto as características do modo de gestão participativa como as da gestão social se complementam e se aplicam aos modelos de coprodução representativa com sustentabilidade e ao de automobilização comunitária, porque esses modelos têm como premissa a participação efetiva da comunidade e de seus cidadãos. A partir dessas considerações, do referencial teórico e da discussão levada a efeito neste ensaio, o quadro que segue identifica as características do modo de gestão de cada um dos modelos de coprodução dos serviços públicos.

\section{Conclusões}

Este ensaio se propôs a identificar as principais características que integram o modo de gestão de cada um dos modelos de coprodução dos serviços públicos. Para alcançar esse propósito foram discutidos os modelos de administração pública, as suas características $e$, a partir delas, foram identificadas as categorias de análise necessárias para se definir o modo de gestão de cada um dos modelos de coprodução dos serviços públicos. Também foi identificada a base teórica que deu sustentação aos argumentos desenvolvidos ao longo do ensaio. A discussão englobou, ainda, os modelos de coprodução dos serviços públicos, os modos de gestão das organizações públicas e os da gestão social.

O ensaio demonstrou que as características inerentes aos modelos de administração pública $e$ aos modelos de coprodução dos serviços públicos guardam uma relação de similaridade entre si, no tocante aos seus modos de gestão. Ainda (STIEVERS, 2002) ficou evidente que os modelos de coprodução que exigem maior envolvimento do cidadão são aqueles que incorporam características do modo de gestão participativo e da gestão social. Por seu turno, chega-se à conclusão de que os modos de gestão participativa e a gestão social, quando utilizados na gestão dos modelos de coprodução, têm uma grande interface e mais se complementam do que simplesmente se somam ou justapõem. Já os modelos de coprodução nominal e funcional, por não exigirem a participação política ativa do cidadão, se ajustam aos modos de gestão tecnoburocrática e de excelência, respectivamente.

As características que foram identificadas do modo de gestão de cada modelo de coprodução emprestam a pesquisa um novo referencial sobre a direção, coordenação e controle da rede de coprodução. Sob esse ângulo, o conceito que for atribuído ao modo de gestão de cada modelo de coprodução deve incorporar as características do modelo e do respectivo modo de gestão. A gestão da rede, sob esse prisma, não tem um conceito geral, mas um específico para cada modelo de coprodução.

As características do modo de gestão dos modelos de coprodução representativa com sustentabilidade e para a automobilização comunitária têm uma interface com a ciência política e a filosofia, que devem ser consideradas quando esses modos de gestão forem pesquisados, pois a participação, nesses casos, se insere na esfera pública do agir humano, ou seja, na ação política. Também, os trabalhos de pesquisa que focam a gestão da rede de coprodução, em seus diversos modelos, necessitam se beneficiar do mesmo referencial teórico que deu sustentação à identificação das características do modo de gestão de cada um dos modelos de gestão, para que não haja divergência de natureza epistemológica e inconsistência nos seus resultados.

As categorias de análise, identificadas a partir das características dos modelos de administração pública, que serviram de fio condutor deste trabalho na busca das características do modo de gestão de cada um dos modelos de coprodução, se constituem em balizas de futuras pesquisas, razão pela qual é necessário aprofundar a sua elaboração conceitual e teórica. Da mesma forma, a interface entre o modo de gestão das organizações públicas e da gestão social requer estudos aprofundados, além dos que foram apresentados neste ensaio, para que deles possam se beneficiar futuras pesquisas sobre as redes de coprodução dos 
serviços públicos. Este ensaio teve a pretensão de dar os primeiros passos nessa direção, ao identificar as características do modo de gestão de cada um dos modelos de coprodução.

\section{REFERÊNCIAS}

ALFORD, John. Why the Public-Sector Clients coproduce? Toward a Contingency Theory.

Administration and Society, v. 34, n. 1, p. 32-56, Mar. 2002.

ARENDT, Hanna. A condição humana. 11. ed. rev. Tradução Roberto Raposo, revisão técnica: Adriano Correia. Rio de Janeiro: Forense Universitária, 2014.

ARENDT, Hanna. A promessa da política. Rio de Janeiro: Bertrand Brasil Ltda., 2009.

ARNSTEIN, Sherry. R. A Ladder of Citizen Participation. Journal of the American Institute of Planners. Routledge, v. 35, n. 4, p. 216-224, 1969.

BOULLOSA, R. de F., SCHOMMER, P. C. Limites da natureza da inovação ou qual o futuro da gestão social? In: ENCONTRO DA ASSOCIAÇÃO NACIONAL DE PÓSGRADUAÇÃO E PESQUISA EM ADMINISTRAÇÃO, 32., 2008, Rio de Janeiro. Anais..., Rio de Janeiro: ANPAD, 2008. 1 CD ROM.

CANÇADO, Airton Cardoso; SAUSEN, Jorge Oneide; VILLELA, Lamounier Erthal. Gestão social versus gestão estratégica. In: Gestão social e gestão estratégica: experiências em desenvolvimento territorial. Rio de Janeiro: Fundação Getúlio Vargas, 2013. Cap. n. 1, p. 15-86.

CANÇADO, Airton Cardoso; TENÓRIO, Fernando Guilherme; PEREIRA, José Roberto. Gestão social: reflexões teóricas e conceituais. Cad. EBAPE. BR, Rio de Janeiro, v. 9, n. 3, p. 681-703, 2011.

CEPIKU, Denita; GIORDANO, Filippo. Co-Production in Developing Countries: Insights from the community health workers experience. Public Management Review,

Oxford, n. ahead-of-print, p. 1-24, 2013.
CHANLAT, Jean-François. Modos de gestão, saúde e segurança no trabalho. In: DAVEL, Eduardo; VASCONCELLOS, João (Ed.). Recursos humanos e subjetividade. Petrópolis: Vozes, 2000. p. 118-128.

DE MATTIA, Clenia; ZAPELINI, Marcello Beckert. Ética e Coprodução de Serviços Públicos: uma fundamentação a partir de Habermas. In: ENCONTRO NACIONAL DOS CURSOS DE GRADUAÇÃO EM ADMINISTRAÇÃO, 14, 2013, Florianópolis. Anais ..., Florianópolis, ANGRAD, 2013.

DENHARDT, Robert B.; DENHARDT, Janet V. The New Public Service: serving not steering. New York: M. E. Sharpe, 2011.

ETZIONI, Amitai. Organizações complexas. São Paulo, Atlas, 1973.

FADUL, Élvia Mirian Cavalcanti et al. Ensaiando interpretações e estratégias para o campo da administração pública no Brasil. Revista de

Administração Pública-RAP, Rio de Janeiro, v. 46, n. 6, p. 1.437-1.458, 2012.

JAKOBSEN, Morten. Can government initiatives increase citizen coproduction? Results of a randomized field experiment. Journal of Public Administration Research and Theory, Oxford, v. 23, n. 1, p. 27-54, 2013.

KISER, Larry L.; PERCY, Stephen L. The concept of coproduction and its implications for public service delivery. In: THE ANNUAL MEETING OF THE AMERICAN SOCIETY FOR PUBLIC ADMINISTRATION, 1980, San Francisco. Anais... San Francisco: ASPA, 1980. p. 13-16.

KLEIN JR, Vitor Hugo et al. Participação e coprodução em política habitacional: estudo de um programa de construção de moradias em SC. Revista de Administração Pública-RAP, Rio de Janeiro, v. 46, n. 1, p. 25-48, 2012.

OSBORNE, Stephen. P.; RADNOR, Zoe; NASI, Greta. A new theory for public service management? Toward a (public) service-dominant approach. The American Review of Public Administration, Thousand Oaks, v. 43, n. 2, 135-158. 2012. 
PIMENTEL, M. P. C.; PIMENTEL, T. D. Gestão Social: perspectivas, princípios e (De)Limitações. In: ENCONTRO DE ESTUDOS ORGANIZACIONAIS, 6., 2010,

Florianópolis. Anais... Curitiba: ANPAD, 2010. v. 1. p. $1-16$.

PRETTY, Jules N. Participatory learning for sustainable agriculture. World development, v. 23, n. 8, p. 1247 1263, 1995.

RAMOS, Alberto Guerreiro. A Nova ciência das organizações: uma reconceitualização da riqueza das nações. Rio de Janeiro: Fundação Getúlio Vargas, 1981.

RAMOS, Alberto Guerreiro. Administração e contexto brasileiro. Rio de Janeiro: Fundação Getúlio Vargas, 1983.

RAMOS, Alberto Guerreiro. A Sociologia de Max Weber: sua importância para a teoria e a prática da administração. Revista do Serviço Público, Brasília, DF, v. 57, n. 2, p. 267-282, 2006.

RAMOS, Alberto Guerreiro. A modernização em nova perspectiva: em busca do modelo de possibilidade. In: HEIDMANN, Francisco G.; SALM, José F. Políticas públicas e desenvolvimento: bases epistemológicas e modelos de análise. 3. ed. Brasília, DF: Editora Universidade de Brasília, 2014, p. 41-79.

SALM, José Francisco. Coprodução de bens e serviços públicos. In: BOULLOSA, Rosana de Freitas (Org.).

Dicionário para a formação em gestão social. Salvador: CIAGS/UFBA, 2014, p. 42-44.

SALM, José Francisco; MENEGASSO, Maria Ester. Proposta de modelos para a coprodução do bem público a partir das tipologias de participação. In: ENCONTRO CIENTÍFICO DE ADMINISTRAÇÃO DA ASSOCIAÇÃO NACIONAL DE PÓS-GRADUAÇÃO E PESQUISA EM ADMINISTRAÇÃO, 24, 2010, Rio de Janeiro, Anais..., Rio de Janeiro: ANPAD, 2010. CD-ROM.

SCHON, Donald A. Beyond the stable state: public and private learning in a changing society. Harmondsworth: Penguin, 1973.
STIVERS, Camilla. Toward administrative public spaceHannah Arendt meets the municipal housekeepers.

Administration \& Society, Thousand Oaks, v. 34, n. 1, p. 98-102, Mar. 2002.

SUNDEEN, Richard A. Coproduction and Communities Implications for Local Administrators. Administration \& Society, Thousand Oaks, v. 16, n. 4, p. 387-402, 1985.

TAO, Jill L.; MCCABE, Barbara C. Where a Hollow State Casts No Shadow Homeowner Associations in Local Governments. The American Review of Public Administration, Thousand Oaks, v. 42, n. 6, p. 678694, 2012.

VOEGELIN, Eric. Anamnesis. Columbia: University of Missouri Press, 1990.

WEBER, Max. Economia e sociedade. Brasília, DF: Editora Universidade de Brasília, 2004.

WHITE, Sarah C. Depoliticising development: the uses and abuses of participation. Development in Practice, Oxford, v. 6, n. 1, p. 6-15, 1996.

WHITAKER, Gordon P. Coproduction: citizen participation in service delivery. Public Administration Review, Oxford, p. 240-246, 1980. 